\title{
Flow Dynamic Analysis of Core Shooting Process through Experiment and Multiphase Modeling
}

\author{
Changjiang Ni, ${ }^{1}$ Gaochun Lu, ${ }^{2}$ Tao Jing, ${ }^{1}$ and Junjiao $\mathrm{Wu}^{1}$ \\ ${ }^{1}$ School of Materials Science and Engineering, Tsinghua University, Beijing 100084, China \\ ${ }^{2}$ Suzhou Mingzhi Technology Co., Ltd., Suzhou 215217, China \\ Correspondence should be addressed to Tao Jing; jingtao@mail.tsinghua.edu.cn
}

Received 23 August 2016; Revised 21 October 2016; Accepted 31 October 2016

Academic Editor: Pär Jönsson

Copyright (c) 2016 Changjiang Ni et al. This is an open access article distributed under the Creative Commons Attribution License, which permits unrestricted use, distribution, and reproduction in any medium, provided the original work is properly cited.

\begin{abstract}
Core shooting process is the most widely used technique to make sand cores and it plays an important role in the quality of sand cores as well as the manufacture of complicated castings in metal casting industry. In this paper, the flow behavior of sand particles in the core box was investigated synchronously with transparent core box, high-speed camera, and pressure measuring system. The flow pattern of sand particles in the shooting head of the core shooting machine was reproduced with various colored core sand layers. Taking both kinetic and frictional stress into account, a kinetic-frictional constitutive correlation was established to describe the internal momentum transfer in the solid phase. Two-fluid model (TFM) simulations with turbulence model were then performed and good agreement was achieved between the experimental and simulation results on the flow behavior of sand particles in both the shooting head and the core box. Based on the experimental and simulation results, the flow behavior of sand particles in the core box, the formation of "dead zone" in the shooting head, and the effect of drag force were analyzed in terms of sand volume fraction $\left(\alpha_{s}\right)$, sand velocity $\left(\mathbf{V}_{s}\right)$, and pressure variation $(P)$.
\end{abstract}

\section{Introduction}

Core shooting process is the most widely used technique to make sand cores and has attracted continuous attention in metal casting industry with the increase of the demands, complexity, and high quality requirements of castings [1]. Although simple in its concept, the effective use of core shooting process still faces some challenges. Firstly, performance of the core shooting process and the quality of the sand cores are strongly affected by the operative conditions. Secondly, the mechanisms governing the complex flow behavior of sand particles in core shooting process is still unclear and until now trial-and-error method is still the main method to produce sand cores. The efficiency and quality of core shooting process is low and lots of waste core sands are generated. There is a definite need for a detailed analysis of the flow dynamics of core shooting process.

In recent years, research and development have been carried out increasingly to improve the quality of sand cores. However, most effort has gone to the development of new binders system [2] and there are only few studies on the flow dynamics of core shooting process. To investigate the instantaneous sand particle behavior, nonintrusive technique should be used. High-speed photography has been successfully applied in fluidized bed by a number of researchers [35] due to its applicability for various experimental conditions. Wu et al. [6,7] and Winartomo et al. [8] tried to apply high-speed camera to photograph the sand behavior during the core shooting process. The experiments were only used to qualitatively validate the simulation results and their attention was focused on the region of core box while the region of shooting head was ignored.

Besides experiment, numerical simulation was also a useful and powerful tool and can provide valuable insights into the flow dynamics of core shooting process. Wu et al. $[6,7]$ applied two-fluid model (TFM) with kinetic theory of granular flow (KTGF) [9-11] for core shooting process simulation and the sand flow behavior at dilute regions was well predicted. Winartomo et al. [8] modeled the core shooting process in a similar way and qualitatively validated the simulation results with experiments. Bakhtiyarov and Overfelt [1] applied TFM with an empirical approach 


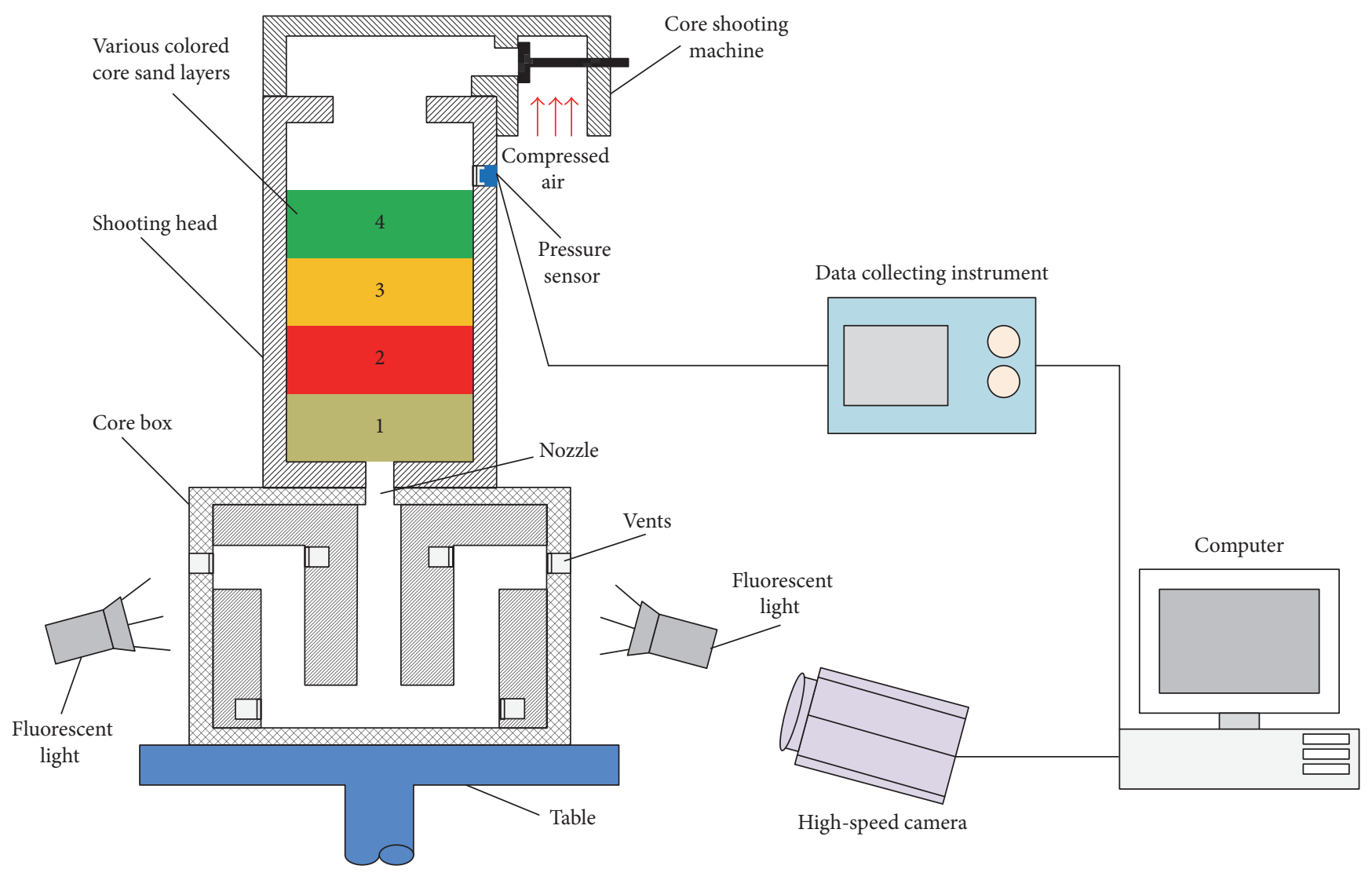

FIGURE 1: Schematic of the experimental apparatus.

assuming a constant viscosity of the solid phase (CVM). In the previous studies, the frictional stress among the particle phase and the turbulence interaction between particle phase and gas phase were not considered reasonably. In addition, the simulations in the previous studies were limited to the region of core box while the effects of shooting head and nozzle were ignored, which could result in some inaccuracy.

It has been shown that very limited research has been performed to investigate the flow dynamics of core shooting process, especially the flow dynamics in the shooting head and the nozzle. In this paper, the flow dynamics were investigated experimentally with various colored core sand layers, transparent core box, high-speed camera, and pressure measuring system. Two-fluid model (TFM) simulations with turbulence model were then performed for the whole regions including the shooting head, the nozzle, and the core box. Based on the simulation and experimental results, the flow behavior of sand particles in the core box was discussed and the formation of "dead zone" in the shooting head was analyzed. Finally, effect of drag force on the flow dynamics of sand particles was investigated.

\section{Experimental Setup}

The experimental apparatus used in this work is illustrated in Figure 1. The core shooting machine is a general one used in industry. In order to facilitate the analysis of flow dynamics, the core box was designed to be a simple shape with multiple changes of flow direction. Silica sand with mean sand diameter of $240 \mu \mathrm{m}$ and bulk density of $1484 \mathrm{Kg} \cdot \mathrm{m}^{-3}$ was used in the core shooting process. "Two-part" cold box resin binder system with total binder level of $1.5 \mathrm{wt} . \%$ and $1: 1$ ratio was mixed with the silica sand in a vane-type mixer for $120 \mathrm{~s}$. Four colored core sand layers were then piled up in the shooting head in succession and every colored layer was leveled. The core shooting process started from abrupt transportation of compressed air into the shooting head. Then the colored sand particles were shot into the core box through the nozzle. Finally, the core box was filled with compacted core sand and the remaining air escaped through vents.

During the core shooting process, a computer controlled high-speed camera (mega speed MS55K, maximum speed: 1300 frames per second) was used to photograph the flow behavior through the transparent front wall (made of plexiglas) of the core box and then the photographs were transferred to computer directly. The flow field in the core box was illuminated by two identical groups of $1000 \mathrm{~W}$ fluorescent lights symmetrically placed beside the core box. Pressure sensor (Keyence AP-C30C) and a computer controlled data acquisition instrument (IMC BUSDAQ) were used to measure the pressure variations, and the collection frequency was set to be $100 \mathrm{HZ}$. After the core shooting process, the core sands in the core box and in the shooting head were cured 
TABLE 1: Kinetic constitutive equations.

\begin{tabular}{|c|c|}
\hline Kinetic stress tensor & $\boldsymbol{\tau}_{s}^{k}=2 \mu_{s}^{k}\left\{\frac{1}{2}\left[\nabla \mathbf{V}_{s}+\left(\nabla \mathbf{V}_{s}\right)^{T}\right]-\frac{1}{3} \nabla \cdot \mathbf{V}_{s} \mathbf{I}\right\}+\left(-P_{s}^{k}+\xi_{s}^{k} \nabla \cdot \mathbf{V}_{s}\right) \mathbf{I}$ \\
\hline Kinetic pressure & $P_{s}^{k}=\rho_{s} \alpha_{s} \theta\left[1+2(1+e) g_{0} \alpha_{s}\right]$ \\
\hline Kinetic shear viscosity & $\mu_{s}^{k}=\frac{4}{5} \alpha_{s}^{2} \rho_{s} d_{s} g_{0}(1+e) \sqrt{\frac{\theta}{\pi}}+\frac{10 \rho_{s} d_{s} \sqrt{\pi \theta}}{96(1+e) \alpha_{s} g_{0}}\left[1+\frac{4}{5} g_{0} \alpha_{s}(1+e)\right]^{2}$ \\
\hline Bulk viscosity & $\xi_{s}^{k}=\frac{4}{3} \alpha_{s}^{2} \rho_{s} d_{s} g_{0}(1+e) \sqrt{\frac{\theta}{\pi}}$ \\
\hline Conductivity of the fluctuating energy & $k_{s}=-2 \alpha_{s}^{2} \rho_{s} d_{s} g_{0}(1+e) \sqrt{\frac{\theta}{\pi}}-\frac{75 \rho_{s} d_{s} \sqrt{\pi \theta}}{384(1+e) g_{0}}\left[1+\frac{6}{5} g_{0} \alpha_{s}(1+e)\right]^{2}$ \\
\hline Dissipation fluctuating energy & $\gamma_{s}=3\left(1-e^{2}\right) \alpha_{s}^{2} \rho_{s} g_{0} \theta\left[\frac{4}{d_{s}}\left(\frac{\theta}{\pi}\right)^{1 / 2}\right]-\nabla \cdot \mathbf{V}_{s}$ \\
\hline
\end{tabular}

respectively and then the cured core sands were removed from the core box and the shooting head in succession.

\section{Multiphase Model}

A two-fluid model (TFM), in which a kinetic-frictional constitutive correlation and the standard $k-\varepsilon-k_{s}-\varepsilon_{s}$ turbulence model were incorporated, was established to simulate the core shooting process.

3.1. Governing Equations. The equations of mass and momentum conservation are solved for each considered phase, and the according governing equations are as follows [12].

For gas phase

$$
\begin{aligned}
& \frac{\partial}{\partial t}\left(\alpha_{g} \rho_{g}\right)+\nabla \cdot\left(\alpha_{g} \rho_{g} \mathbf{V}_{g}\right)=0, \\
& \frac{\partial}{\partial t}\left(\alpha_{g} \rho_{g} \mathbf{V}_{g}\right)+\nabla \cdot\left(\alpha_{g} \rho_{g} \mathbf{V}_{g} \mathbf{V}_{g}\right) \\
& \quad=\alpha_{g} \nabla \cdot \tau_{g}-\beta\left(\mathbf{V}_{g}-\mathbf{V}_{s}\right)-\alpha_{g} \nabla P_{g}+\alpha_{g} \rho_{g} \mathbf{g} .
\end{aligned}
$$

For particle phase

$$
\begin{aligned}
& \frac{\partial}{\partial t}\left(\alpha_{s} \rho_{s}\right)+\nabla \cdot\left(\alpha_{s} \rho_{s} \mathbf{V}_{s}\right)=0, \\
& \frac{\partial}{\partial t}\left(\alpha_{s} \rho_{s} \mathbf{V}_{s}\right)+\nabla \cdot\left(\alpha_{s} \rho_{s} \mathbf{V}_{s} \mathbf{V}_{s}\right) \\
& \quad=\nabla \cdot \tau_{s}+\beta\left(\mathbf{V}_{g}-\mathbf{V}_{s}\right)-\alpha_{s} \nabla P_{g}-\nabla P_{s}+\alpha_{s} \rho_{s} \mathbf{g},
\end{aligned}
$$

where $\alpha_{g}$ is the volume fraction of air, $\alpha_{s}$ is the sand volume fraction, $\rho_{g}$ is the air density, $\rho_{s}$ is the sand density, $\mathbf{V}_{g}$ is velocity vector of air, $\mathbf{V}_{s}$ is the velocity vector of sand, $\boldsymbol{\tau}_{g}$ is shear stress tensor of gas phase, $\boldsymbol{\tau}_{s}$ is the shear stress tensor of sand phase, $\beta$ is the drag coefficient, $P_{g}$ is the gas pressure, $P_{s}$ is the sand pressure, and $\mathbf{g}$ is the gravitational acceleration vector.

The interphase forces between gas phase and sand particle phase consist of virtual mass, drag force, and lift. As $\rho_{s} / \rho_{g} \approx$ 2000, the virtual mass effect is insignificant and can be neglected, as shown by Stock [13]. On the other hand, the lift force is also neglected because the sand particle phase is relatively small $(240 \mu \mathrm{m})$ and the lift force is more significant for larger particles. Therefore, drag force is the only force included in the interphase forces, as shown in (3).

Besides the mass and momentum equations, a fluctuation kinetic energy equation is also solved to account for the conservation of the fluctuation energy of particle phase in the kinetic theory of granular flow (KTGF) [11]. The KTGF, which is initialed by Jenkins and Savage [9], Lun et al. [10], and Ding and Gidaspow [11], has been derived from the kinetic theory of dense gases. A quantity named the "granular temperature," $\theta$, which is analogous to the thermal temperature in the kinetic theory of gases, is defined as $\theta=\left\langle\mathbf{C}^{2}\right\rangle / 3$, where $\mathbf{C}$ is the particle random fluctuating velocity.

$$
\begin{aligned}
& \frac{\partial}{\partial t}\left(\alpha_{s} \rho_{s} \theta\right)+\nabla \cdot\left(\alpha_{s} \rho_{s} \mathbf{V}_{s} \theta\right) \\
& \quad=\frac{2}{3}\left[\left(\boldsymbol{\tau}_{s}-P_{s} \cdot \mathbf{I}\right): \nabla \mathbf{V}_{s}-\nabla \cdot\left(k_{s} \nabla \theta\right)-\gamma_{s}\right],
\end{aligned}
$$

where $\gamma_{s}$ is the collisional energy dissipation and $k_{s}$ is the conductivity of the fluctuating energy.

Then the kinetic part of particle shear stress $\tau_{s}^{k}$ and particle pressure $P_{s}^{k}$ can be computed as a function of granular temperature at any time and position. Table 1 lists the kinetic constitutive equations derived from KTGF and a comprehensive discussion of KTGF can be found in Gidaspow [12].

3.2. Kinetic-Frictional Constitutive Correlation. In kineticfrictional model, it is assumed that the kinetic and frictional stresses can be treated in an additive manner [14, 15]:

$$
\begin{aligned}
& \mu_{s}=\mu_{s}^{k}+\mu_{s}^{f}, \\
& P_{s}=P_{s}^{k}+P_{s}^{f} .
\end{aligned}
$$

$\mu_{s}^{k}$ and $P_{s}^{k}$ are the kinetic part of particle phase viscosity and particle phase pressure, respectively, and they are defined from the KTGF. In KTGF, it is assumed that stresses arise because of collisional transfer of momentum and the expressions of $\mu_{s}^{k}$ and $P_{s}^{k}$ can be found in Table 1. At high particle volume fractions, the dominant forces are the frictional stress. 
$\mu_{s}^{f}$ and $P_{s}^{f}$ are the frictional part of particle phase viscosity and particle phase pressure, respectively, and they are associated with sustained particle contact at high sand volume concentration [16]. It is common to model the frictional stress by a combination of the normal stress correlation proposed by Johnson et al. [17] and the rigid-plastic rheological model proposed by Schaeffer [18]:

$$
P_{s}^{f}\left(\alpha_{s}\right)= \begin{cases}F \frac{\left(\alpha_{s}-\alpha_{\min }\right)^{c}}{\left(\alpha_{\max }-\alpha_{s}\right)^{s}} & \alpha_{s}>\alpha_{\min } \\ 0 & \alpha_{s} \leq \alpha_{\min },\end{cases}
$$

where $F, c, s$, and $\alpha_{\text {min }}$ are empirical constants and assigned $0.05,2,5$, and 0.5 , respectively.

$$
\mu_{s}^{f}=\frac{P_{s}^{f}\left(\alpha_{s}\right) \sqrt{2} \sin \phi}{2 \sqrt{\mathbf{D}_{\mathbf{i j}}: \mathbf{D}_{\mathbf{i j}}}},
$$

where

$$
\mathbf{D}_{\mathbf{i j}}=\frac{1}{2}\left\{\nabla \mathbf{V}_{s}+\left(\nabla \mathbf{V}_{s}\right)^{T}\right\}-\frac{1}{3}\left(\nabla \cdot \mathbf{V}_{s}\right) \mathbf{I} .
$$

3.3. Turbulence Model. In the core shooting process, the gas phase Reynolds number and the sand particle concentration are high. Thus it is necessary to treat both gas phase and sand particle phase as turbulent flow. Based on the $k-\varepsilon-k_{s}-\varepsilon_{s}$ turbulence model, the turbulent kinetic energy and dissipation rate equation are given by

$$
\begin{aligned}
& \frac{\partial}{\partial t}\left(\alpha_{i} \rho_{i} k_{i}\right)+\nabla \cdot\left(\alpha_{i} \rho_{i} k_{i} \mathbf{U}_{i}\right)=\nabla \cdot\left(\alpha_{i} \frac{\mu_{t, i}}{\sigma_{k}} \nabla k_{i}\right) \\
& +\left(\alpha_{i} G_{k, i}-\alpha_{i} \rho_{i} \varepsilon_{i}\right)+\beta\left(C_{l i} k_{l}-C_{i l} k_{i}\right)-\beta\left(\mathbf{U}_{l}-\mathbf{U}_{i}\right) \\
& \quad \cdot \frac{\mu_{t, l}}{\alpha_{l} \sigma_{l}} \nabla \alpha_{l}+\beta\left(\mathbf{U}_{l}-\mathbf{U}_{i}\right) \frac{\mu_{t, i}}{\alpha_{i} \sigma_{i}} \nabla \alpha_{i}, \\
& \frac{\partial}{\partial t}\left(\alpha_{i} \rho_{i} \varepsilon_{i}\right)+\nabla \cdot\left(\alpha_{i} \rho_{i} \varepsilon_{i} \mathbf{U}_{i}\right)=\nabla \cdot\left(\alpha_{i} \frac{\mu_{t, i}}{\sigma_{\varepsilon}} \nabla \varepsilon_{i}\right) \\
& +\frac{\varepsilon_{i}}{k_{i}}\left(C_{1 \varepsilon} \alpha_{i} G_{k, i}-C_{2 \varepsilon} \alpha_{i} \rho_{i} \varepsilon_{i}\right)+C_{3 \varepsilon} \\
& \quad \cdot \frac{\varepsilon_{i}}{k_{i}}\left[\beta\left(C_{l i} k_{l}-C_{i l} k_{i}\right)-\beta\left(\mathbf{U}_{l}-\mathbf{U}_{i}\right) \frac{\mu_{t, l}}{\alpha_{l} \sigma_{l}} \nabla \alpha_{l}\right. \\
& \left.+\beta\left(\mathbf{U}_{l}-\mathbf{U}_{i}\right) \frac{\mu_{t, i}}{\alpha_{i} \sigma_{i}} \nabla \alpha_{i}\right]
\end{aligned}
$$

where $k_{i}$ is the turbulent kinetic energy, $\mathbf{U}_{i}$ ( $i=$ gas, particle) is the phase-weighted velocity, $\varepsilon_{i}$ is the turbulent energy dissipation rate, $G_{k, i}$ is the production of turbulent kinetic energy, and $\mu_{t, i}$ is the turbulent viscosity given by

$$
\mu_{t, i}=\rho_{i} C_{\mu} \frac{k_{i}^{2}}{\varepsilon_{i}} .
$$

3.4. Simulation Sets. The numerical methods used were implicit backward and first-order upwind for time discretization and discretization of the convective term, respectively.
The set of governing equations were discretized into linear equations using SIMPLEC algorithm by means of FLUENT. Relaxation factors were essential to obtain convergent results in iterative schemes and were set to be 0.1 for all the variables in this work. A convergence criterion of 0.001 was specified as the relative error and the time step used was $1 \times 10^{-5} \mathrm{~s}$. The simulations were conducted in a $2 \mathrm{D}$ Cartesian space. According to Andrews IV et al. [19], grid size should be of the order of 10 particle diameters to get grid-independent simulation results, corresponding to $2.5 \mathrm{~mm}$ grid in this study. Thus a finer $2 \mathrm{~mm} \times 2 \mathrm{~mm}$ grid was used in the following simulations and the time step used was $1 \times 10^{-5} \mathrm{~s}$. Simulations were carried out for the whole domain including the shooting head, the nozzle, and the core box, as shown by Figure 2 . The pressure curve measured by the pressure sensor was used and further simplified to set the inlet pressure (Figure 2) and the atmosphere pressure was prescribed on the vents as pressure outlet. At the wall, no slip condition was employed for the gas phase and partial slip condition proposed by Johnson and Jackson [20] was applied for the sand particle phase.

$$
\begin{aligned}
\boldsymbol{\tau}_{s w}= & \frac{\sqrt{3}}{6} \pi \rho_{s} g_{0} \varphi \frac{\alpha_{s}}{\alpha_{\max }} \sqrt{\theta} \mathbf{V}_{s w}, \\
q_{w}= & \frac{\sqrt{3}}{6} \pi \rho_{s} g_{0} \varphi \frac{\alpha_{s}}{\alpha_{\max }} \sqrt{\theta}\left|\mathbf{V}_{s w}\right|^{2} \\
& -\frac{\sqrt{3}}{4} \pi \rho_{s} g_{0}\left(1-e_{w}^{2}\right) \frac{\alpha_{s}}{\alpha_{\max }} \theta^{3 / 2}
\end{aligned}
$$

where $\varphi$ is the specularity coefficient whose value depends on the large-scale roughness of the wall and its value ranges from 0 for free slip boundary condition to 1 for no slip boundary condition, $q_{w}$ is the flux of pseudothermal energy towards the wall, $e_{w}$ is the restitution coefficient for collisions between particles and the wall, and $g_{0}$ is the radial distribution function and it is taken to be [10]

$$
g_{0}=\left[1-\left(\frac{\alpha_{s}}{\alpha_{\max }}\right)^{1 / 3}\right]^{-1}
$$

The gas velocity and the sand velocity in the whole region were set to zero at the initial time. The simulation was initialed with the sand volume fraction in the region of shooting head and the regions of core box and nozzle, respectively, being 0.56 and zero. Table 2 gives the modeling parameters used in simulations. According to Andrews IV et al. [19] and Benyahia et al. [21], the specularity coefficient $\varphi$ was set to be 0.002 , which was a nearly free slip boundary condition. The angle of internal friction was set to be 0.3 according to Winartomo et al. [8].

\section{Results and Discussions}

4.1. Effect of Restitution Coefficient. The restitution coefficient $e$ is measurement of the inelasticity of the particle-particle collisions and its value ranges from 0 for perfectly inelastic to 1 for perfectly elastic particles. It was reported that the 


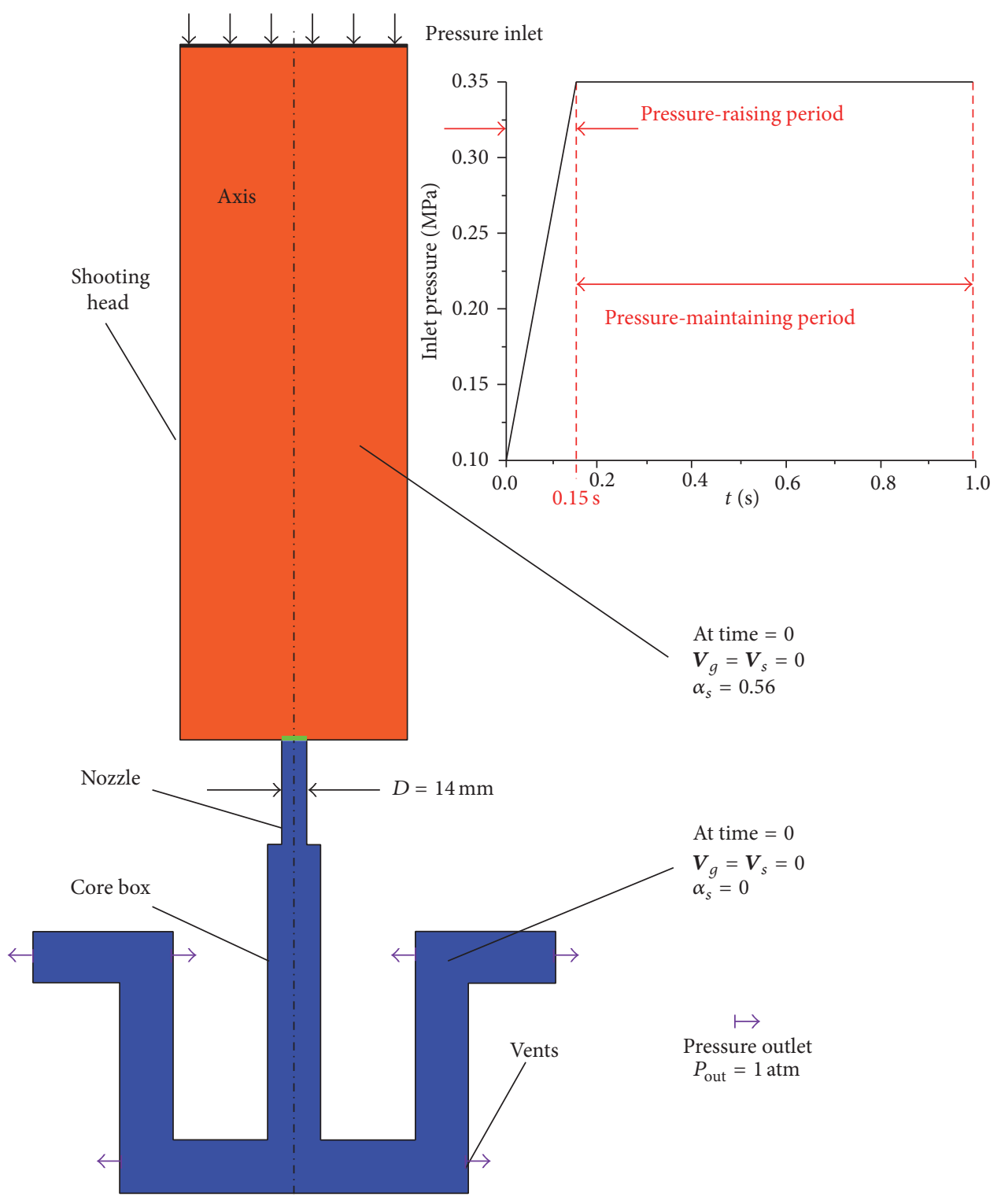

FIgURE 2: Simulation sets and the setting of inlet pressure.

TABLE 2: Modeling parameters.

\begin{tabular}{lcc}
\hline Property & Symbol & Value \\
\hline Sand density $\left(\mathrm{kg} \mathrm{m}^{-3}\right)$ & $\rho_{s}$ & 2650 \\
Mean sand diameter $(\mu \mathrm{m})$ & $d_{s}$ & 240 \\
Restitution coefficient & $e$ & $0.5,0.8,0.9,0.99$ \\
Particle-wall restitution coefficient & $e_{w}$ & 0.8 \\
Max. sand volume fraction & $\alpha_{\max }$ & 0.63 \\
Minimum sand volume fraction for transition to consider frictional stress & $\alpha_{\min }$ & 0.5 \\
Angle of internal fraction & $\phi$ & 0.3 \\
Specularity coefficient & $\varphi$ & 0.002 \\
\hline
\end{tabular}




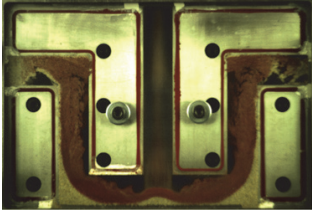

(a)

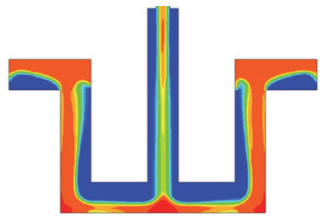

(c)

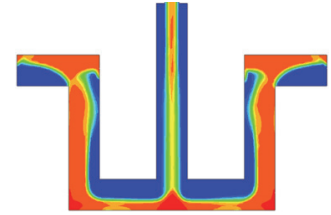

(b)

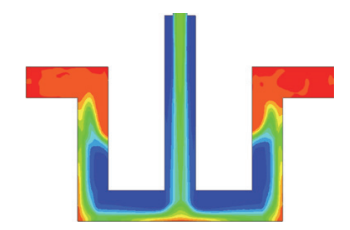

(e)

FIGURE 3: Comparison of (a) experimental result with predicted instantaneous sand volume fraction for (b) $e=0.5$, (c) $e=0.8$, (d) $e=0.9$, and (e) $e=0.99(t=160 \mathrm{~ms})$.

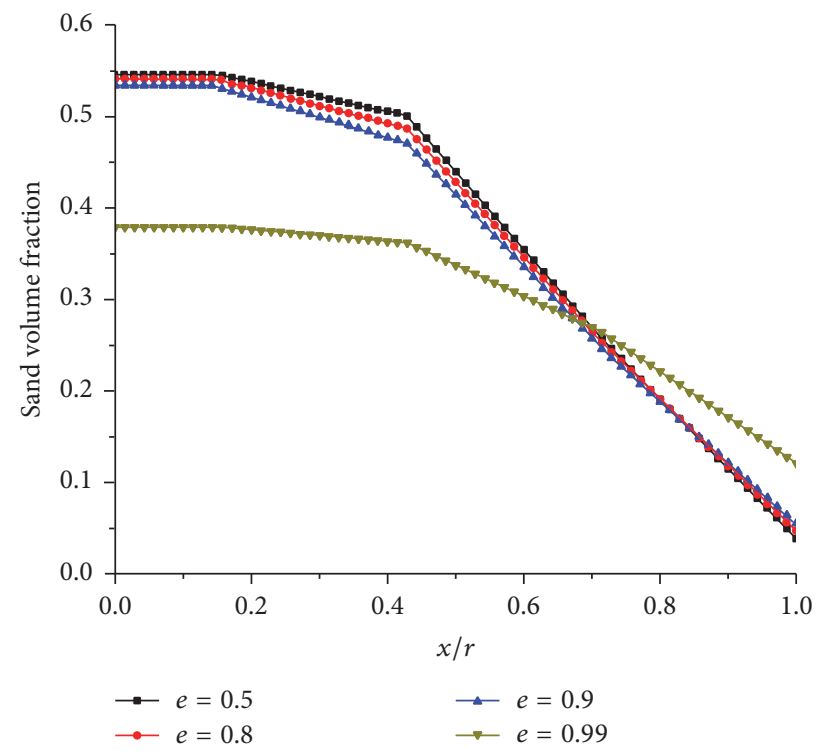

(a)

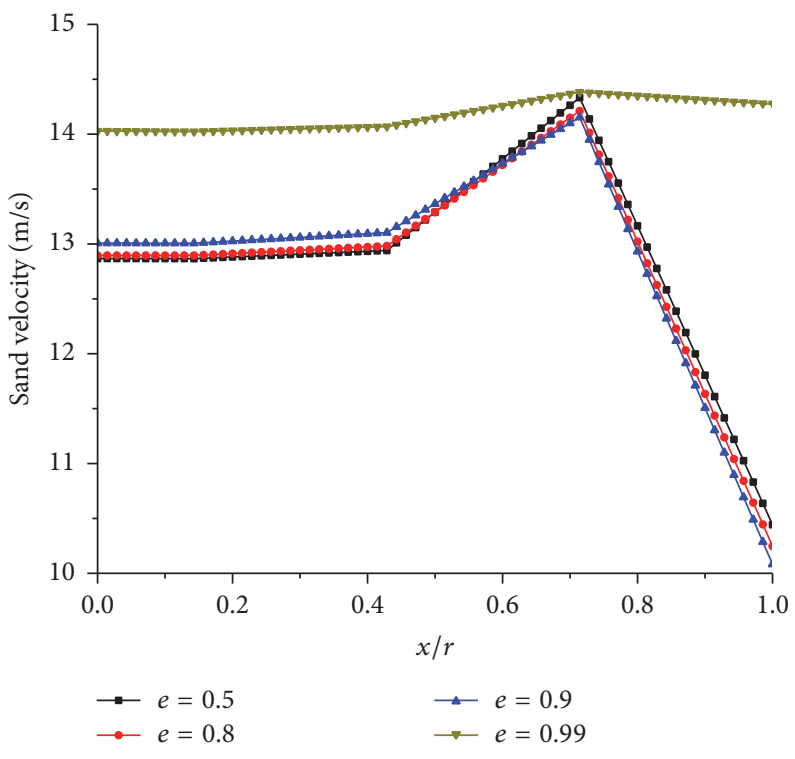

(b)

Figure 4: The distribution of (a) sand volume fraction and (b) sand velocity at the nozzle for different value of restitution coefficient $e$ ( $t=160 \mathrm{~ms}, x$ is the distance to the axis, and $r$ is the radius of the nozzle).

restitution coefficient $e$ is an important empirical parameter in the KTGF based CFD models and affects directly the flow dynamics of gas-solids flow [22-24]. Four values of $e$, that is, $0.5,0.8,0.9$, and 0.99 , were tested in this work to study the influence of the restitution coefficient and find a better fit for the core shooting process. Figure 3 shows the comparison of experimental result with predicted instantaneous sand volume fraction for the four values of $e$ and it is clear that the case of $e=0.99$ shows a larger difference with the experimental result. The sand volume fraction for $e=0.99$ is lower than the other three cases at the unfilled region, while it is higher than the other three cases at the end of the core box at $t=160 \mathrm{~ms}$. To quantitatively discuss the effects of restitution coefficient, distributions of sand volume fraction and sand velocity at the nozzle are compared for the four cases and shown in Figure 4. When increasing the restitution 

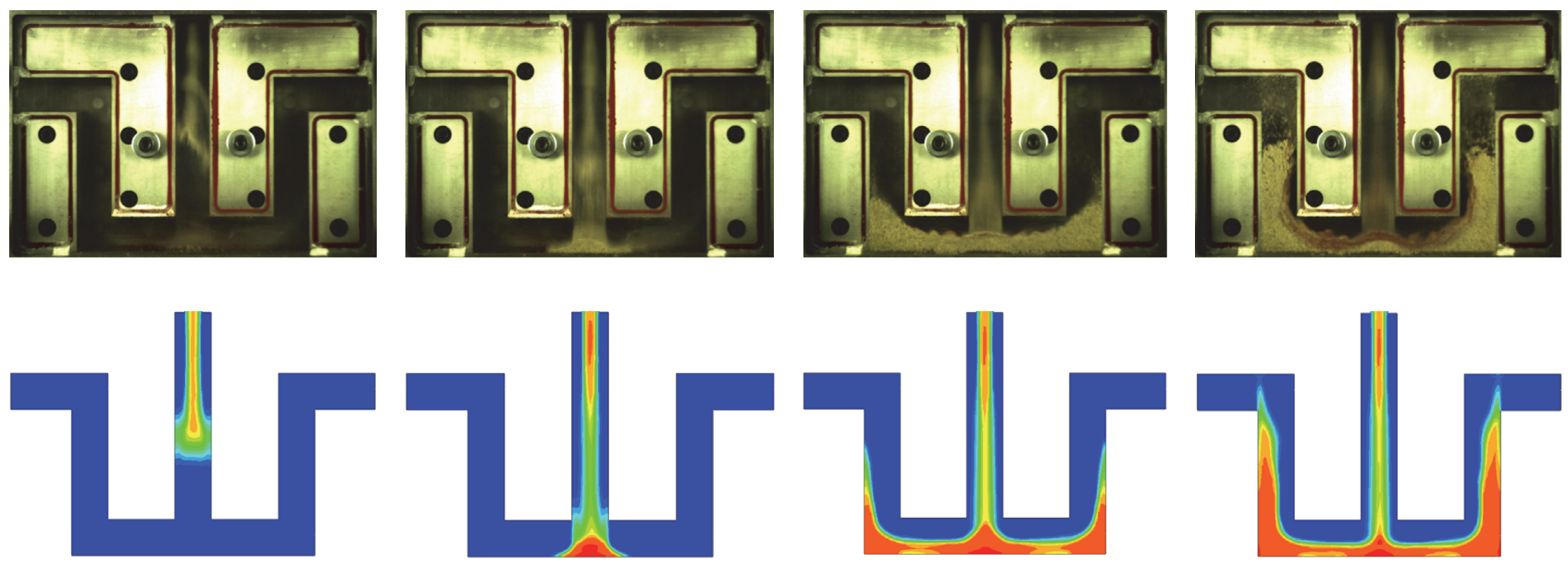

$50 \mathrm{~ms}$

$70 \mathrm{~ms}$

$110 \mathrm{~ms}$

$130 \mathrm{~ms}$
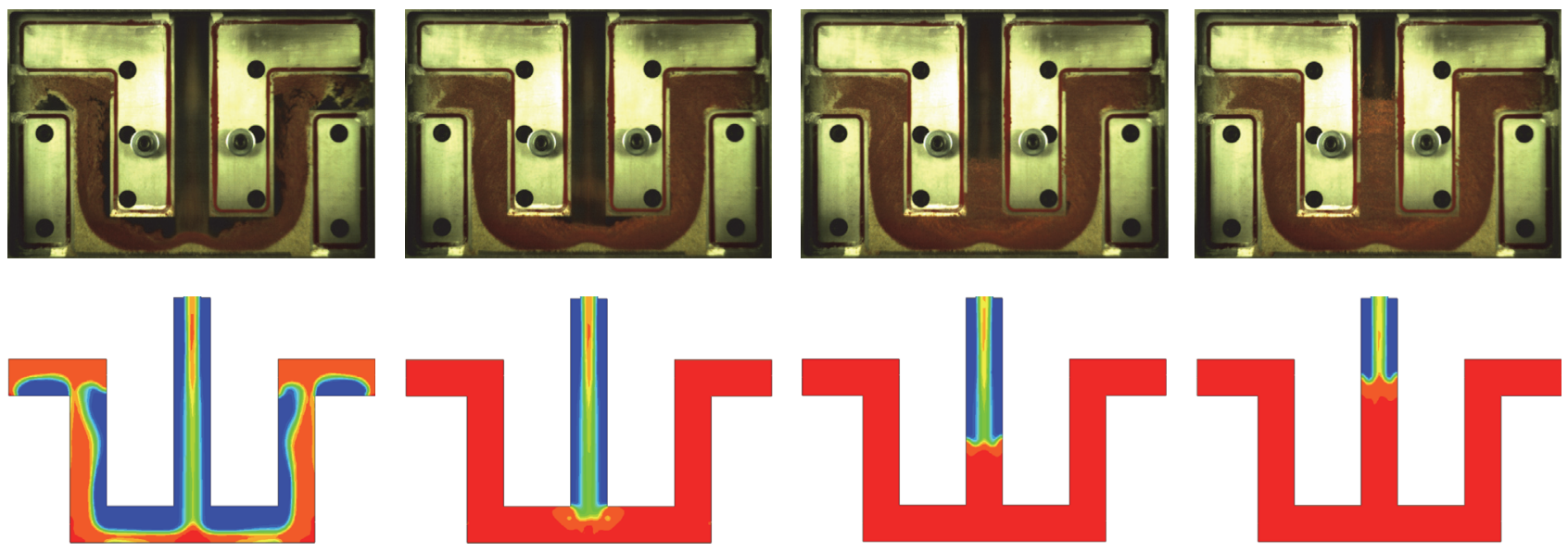

$290 \mathrm{~ms}$

$330 \mathrm{~ms}$

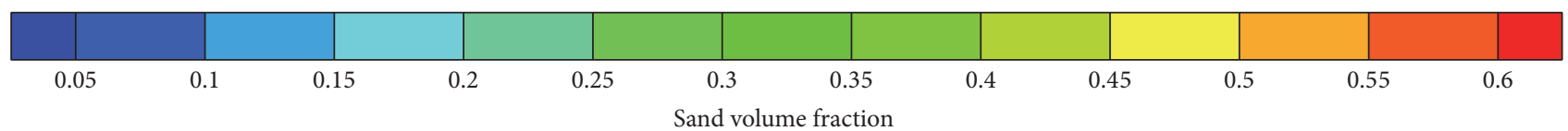

FIGURE 5: Comparison of simulated maps of sand volume fraction with experimental photo sequences.

coefficient from 0.9 to 0.99 , a significant decrease of sand volume fraction and an increase of sand velocity at the nozzle are observed. The effect of restitution coefficient is not critical from $e=0.5$ to $e=0.9$ and a value of 0.9 was used in the rest of the article.

4.2. Flow Behavior of Sand Particles. Figure 5 shows the comparison of simulated maps of sand volume fraction with experimental photo sequences. It is observed that the simulation results predict well the filling process of sand particles in the core box. Sand particles are fed into the core box with compressed air and they move downward with a mushroom-like front-end $(t=50 \mathrm{~ms})$. When sand flow reaches the bottom of the core box, a sand pile is formed and sand particles move laterally towards the sidewall $(t=70 \mathrm{~ms}-$ $t=110 \mathrm{~ms}$ ). Subsequently, sand particles move upward along the sidewall and then laterally along the upper wall of the core box $(t=110 \mathrm{~ms}-t=160 \mathrm{~ms})$. At $t=160 \mathrm{~ms}$, an arch-bridge like porosity is formed at the end of the core box, which is accurately predicted by the simulation results. The far end, the side, and the bottom part of the core box is filled in succession and finally sand particles pile up uniformly till the core box is completely filled $(t=160 \mathrm{~ms}-t=330 \mathrm{~ms})$. Figure 6 shows the evolution maps of sand velocity and streamlines in the core box. The streamlines show clearly the flow behavior of sand particles during the core shooting process and it is consistent with the filling process just described. The global sand velocity in the core box increases within the pressureraising period and then decreases, as shown in Figure 6. For an instantaneous distribution of the sand velocity, there is a significant reduction of the sand velocity at the bottom and the sidewall of the core box, which is because the normal velocity of the sand particle phase is eliminated when sand particles collide with the wall of the core box.

Figure 7(a) shows the variation of sand volume fraction at the nozzle. It can be seen that the sand volume fraction increases sharply when sand particles start getting into the core box through the nozzle, and then it reduces to a steady 


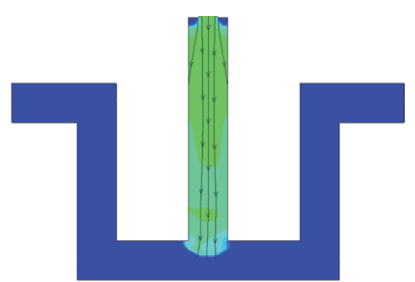

$50 \mathrm{~ms}$

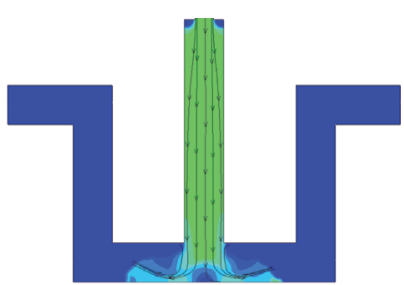

$70 \mathrm{~ms}$

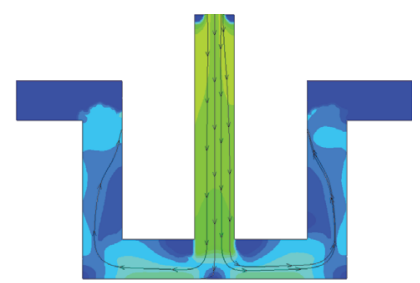

$110 \mathrm{~ms}$

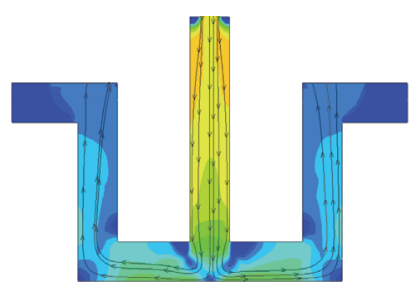

$130 \mathrm{~ms}$

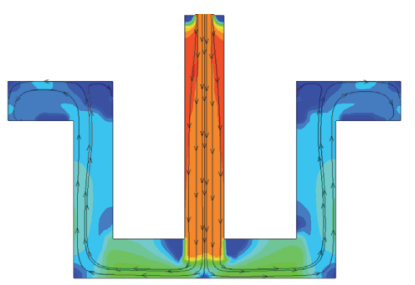

$160 \mathrm{~ms}$

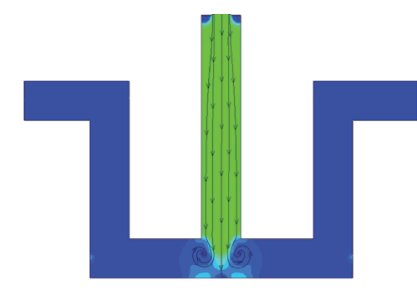

$260 \mathrm{~ms}$

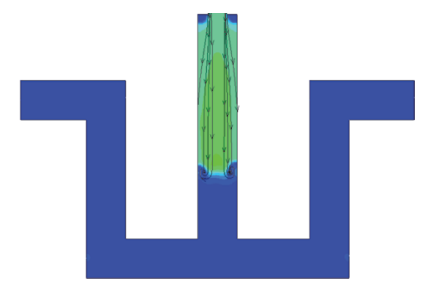

$290 \mathrm{~ms}$

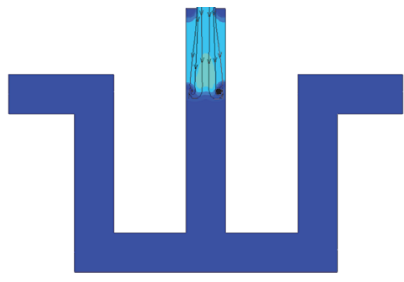

$330 \mathrm{~ms}$

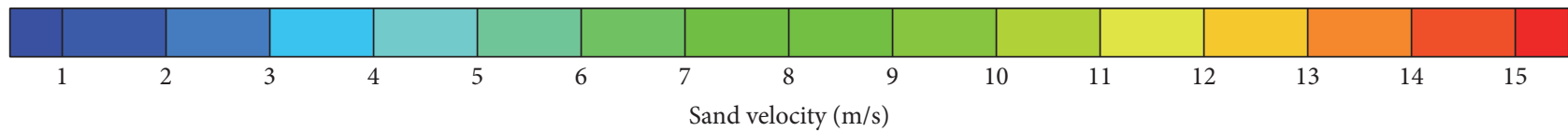

FIGURE 6: Evolution maps of sand velocity and streamlines in the core box.

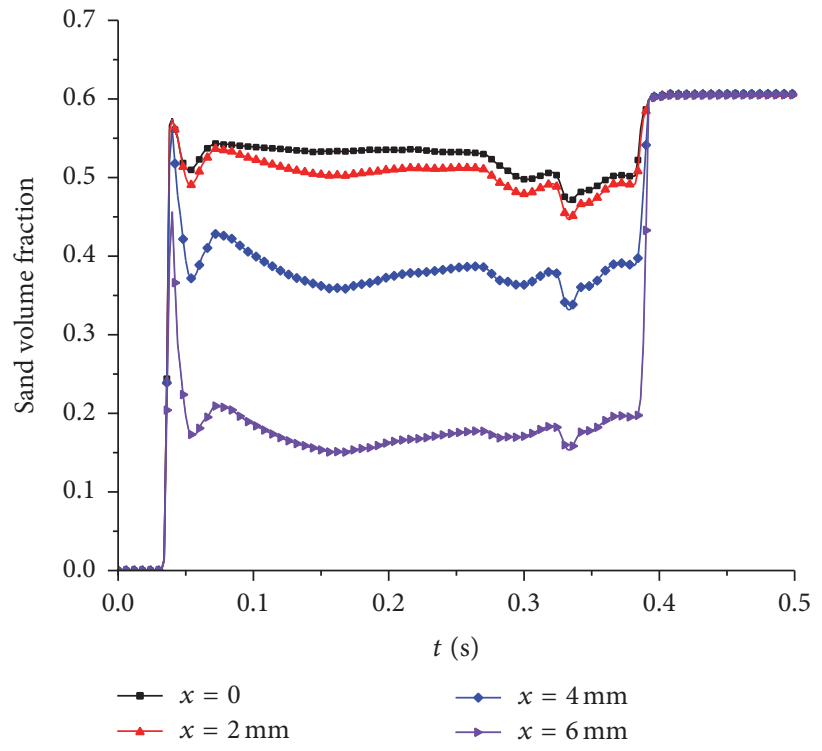

(a)

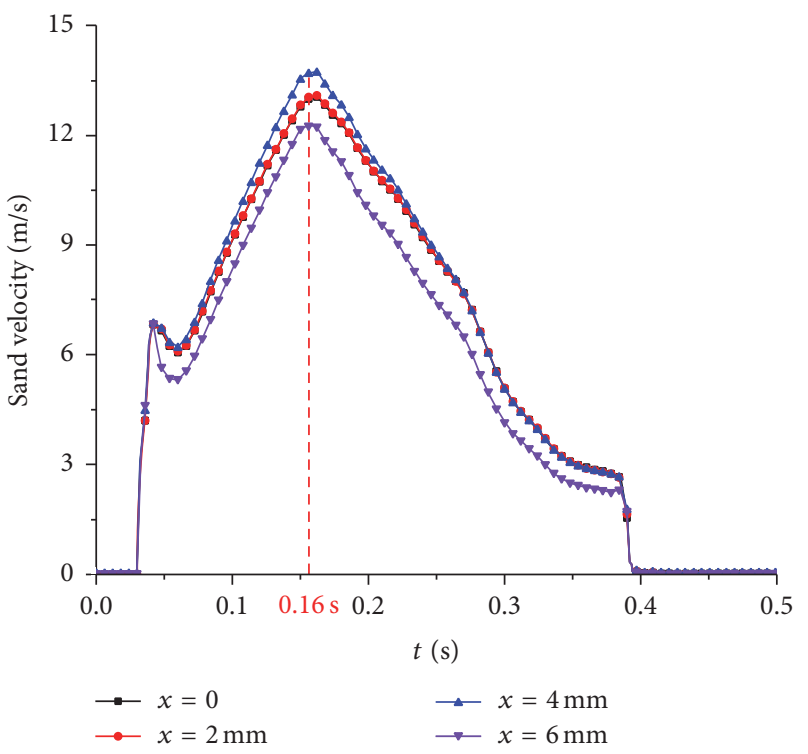

(b)

FIgURE 7: The variations of (a) sand volume fraction and (b) sand velocity at the nozzle over time ( $x$ is the distance to the axis).

condition where no significant variation occurs in the sand volume fraction. Additionally, there is a significant decrease in the sand volume fraction from the middle $(x=0)$ to the border of the nozzle $(x=6 \mathrm{~mm})$, which indicates the assumption of constant and uniform sand volume fraction at the nozzle [6-8] is improper. The variation of sand velocity at the nozzle is shown in Figure 7(b), it can be seen that the sand velocity rises rapidly within the pressure-raising period, and then it declines gradually till the end of core shooting process. The variation of sand velocity is consistent with the variation of pressure difference $(\Delta P)$ between the pressure values above
$\left(P_{\text {up }}\right)$ and below $\left(P_{\text {down }}\right)$ the nozzle (Figure 8$)$. This is because of the fact that pressure difference is a main force exerting on the sand particles, according to (3), and thus it can directly influence the sand velocity.

4.3. Formation of "Dead Zone" in the Shooting Head. "Dead zone" is the stagnant zone in the shooting head and it can significantly decrease the utilization of core sands, increase the workload of cleanup, and leads to waste sand cores. Therefore, the formation of "dead zone" is analyzed based on the simulation and experimental results. 


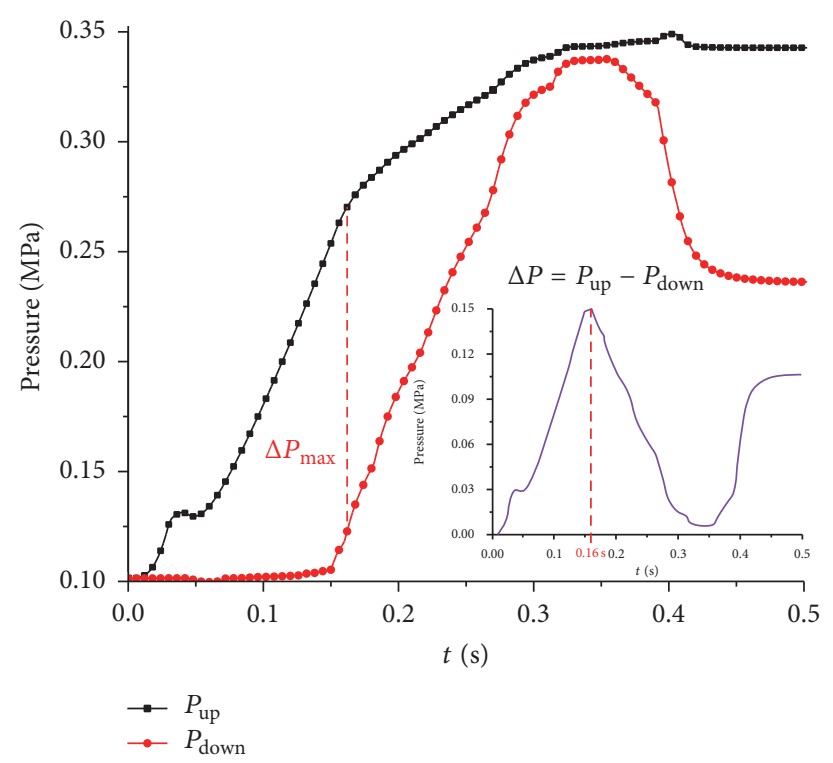

FIgURE 8: The variations of pressure values above and below the nozzle over time.

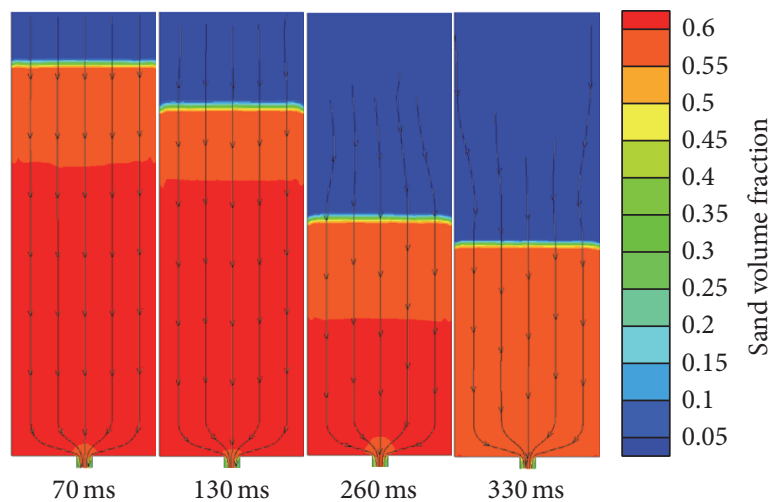

FIGURE 9: Simulated maps of sand volume fraction and streamlines in the shooting head.

The simulated map of sand volume fraction and streamlines in the shooting head is shown in Figure 9. The region far above the nozzle is characterized by a uniform sand volume fraction where the sand particles are in nearly plug flow. With core sands continuously fed into the core box, the sand volume fraction above the nozzle is lower than the adjacent domains and thus the region above the nozzle is constantly supplied with sand particles from the upper part of the shooting head. Therefore, the height of the core sand in the shooting head decreases continuously during the core shooting process, and the sand velocity direction is vertical downward in the region far above the nozzle. Figure 10(a) shows the sand velocity vector in the bottom region of the shooting head with sand velocity distribution superimposed. The region between the nozzle and the wall is characterized by a nearly stagnant zone. As sand particles approach the nozzle, the velocity increases rapidly and the sand particle flow converges towards the nozzle. Then, a lower sand volume fraction region is formed above the nozzle and sand particles right above the region were firstly supplied to this lower sand volume fraction region, as show in Figure 10(c). As shown in Figure 10(b), the angle between the velocity vectors at left border and right border of the entrance is $95^{\circ}$, which is similar to the experimental result $\left(92^{\circ}\right.$ in Figure $\left.10(\mathrm{c})\right)$. The observed results indicate that the region outside the angle range (indicated in Figure 10) is characterized as the stagnant region and forms the "dead zone" in the shooting head.

4.4. Effect of Drag Force. Drag coefficient of Huilin et al. [25] was incorporated and drag modification was introduced by replacing $\beta$ with $\beta^{*}$ to study the effect of drag force.

$$
\beta^{*}=C * \beta
$$

Comparison of simulated maps of sand volume fraction for drag modification coefficient $(C)$ of $1,0.5$, and 0.05 is shown in Figure 11. As particles accelerated down after the nozzle, there is a substantial decrease in the sand volume fraction 


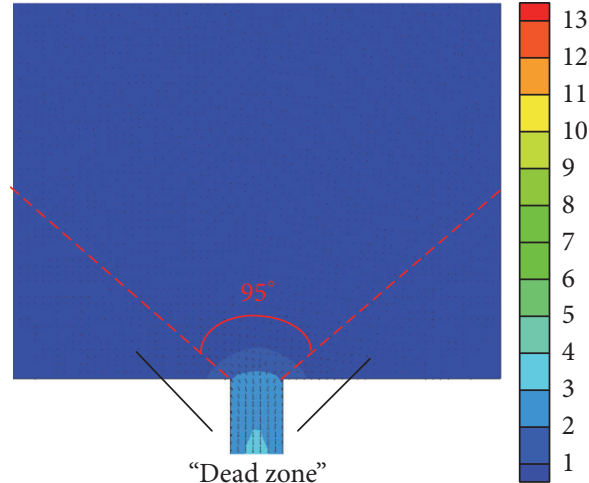

(a)

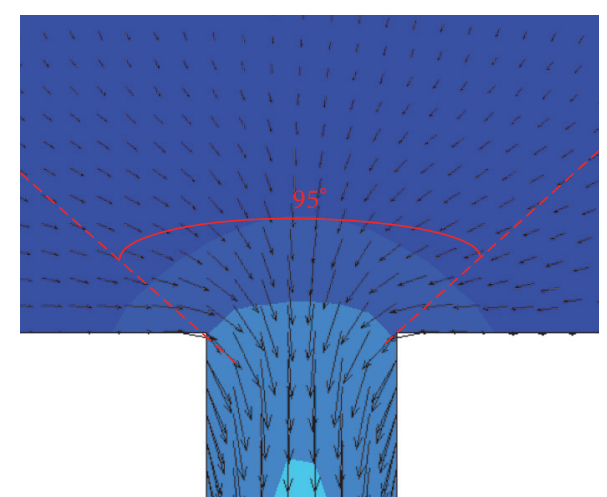

(b)

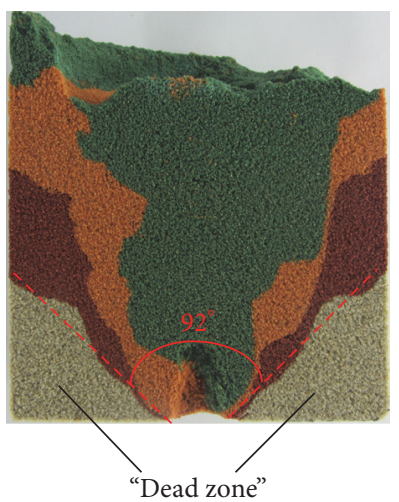

(c)

Figure 10: (a) Vector plots of sand velocity for $t=330 \mathrm{~ms}$ with sand velocity distribution superimposed, (b) magnification of the entrance region in (a), and (c) the state of the colored core sand in the shooting head after core shooting process.

accompanied by a simultaneous dilation, which leads to a mushroom-like front-end (shown in Figure 11(a)). When the modification coefficient decreased from 1 to 0.5 , no obvious difference is obtained (Figure 11(b)). However, with the modification coefficient decreased from 0.5 to 0.05 , the dilation is significantly suppressed and thus no mushroomlike front-end is formed, as shown in Figure 11(c).

Figure 12 shows the instantaneous sand volume fraction distribution at the nozzle and the variation of the sand volume fraction at nozzle over time for the three different modification coefficients. The distribution of sand volume fraction at the nozzle is similar to that described in Section 4.2: higher at the middle of the nozzle and lower at the border. Sand volume fraction at the middle of the nozzle is almost the same for the three modification coefficients while it decreases significantly with lower modification coefficient $(C=0.5,0.05)$ at $x / r>0.14$, as clearly shown in Figure 12(a). To confirm this conclusion, the variations of sand volume fraction for $C=1$ and $C=0.05$ are compared and shown in Figure 12(b). A consistent conclusion can be made that sand volume fraction close to centerline of the nozzle keeps unchanged while it decreases significantly at the region close to border of the nozzle with the decrease of modification coefficient.

\section{Conclusions}

The flow dynamics of core shooting process were studied by combination of experiments and computational fluid dynamics (CFD) simulations. Using various colored core sand layers, transparent core box, high-speed camera, and pressure measuring system, the flow behavior of sand particles during the core shooting process was investigated synchronously. By incorporating the kinetic theory of granular flow, kineticfrictional constitutive correlation, and turbulence model, a two-fluid model (TFM) was established to study the flow dynamics of core shooting process and reasonable agreement was obtained between simulations and experiments. Accordingly, the following conclusions can be drawn:

(1) The variation of sand velocity at the nozzle is consistent with the variation of pressure difference $(\Delta P)$ : the sand velocity rises rapidly within the pressure-raising period, and then it declines gradually till the end of core shooting process. The sand volume fraction at the nozzle keeps almost the same after the initial $0.06 \mathrm{~s}$ and there is a significant decrease of sand volume fraction from the centerline to the border of the nozzle. 


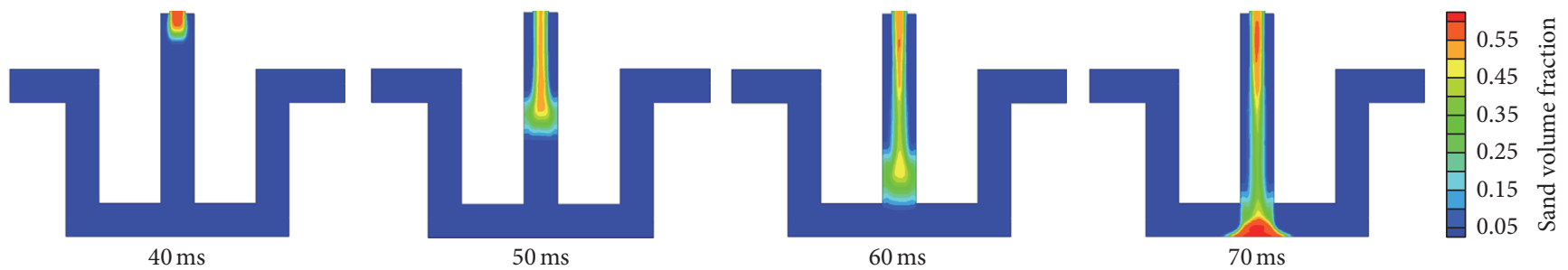

(a)

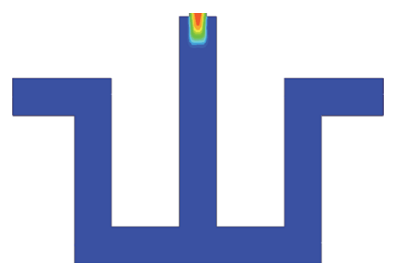

$40 \mathrm{~ms}$

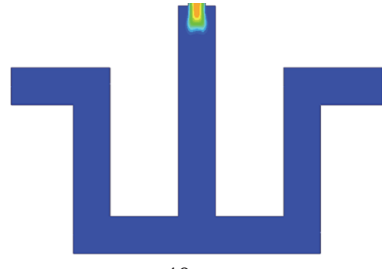

$40 \mathrm{~ms}$

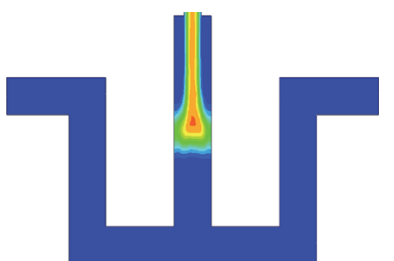

$50 \mathrm{~ms}$

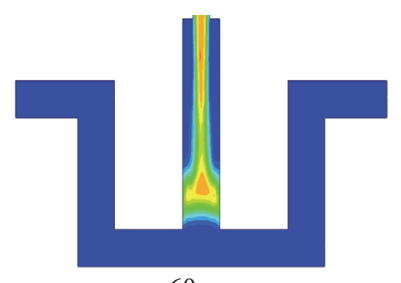

$60 \mathrm{~ms}$

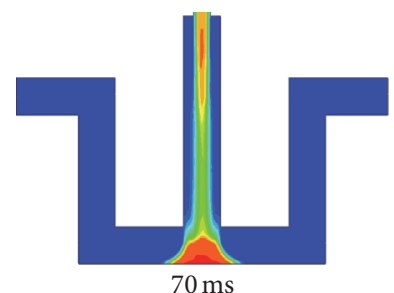

$70 \mathrm{~ms}$

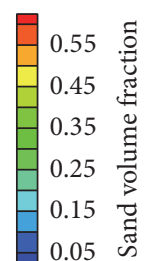

0.05 กี

(b)

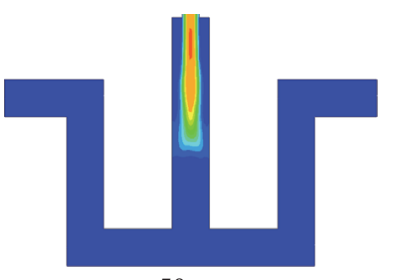

$50 \mathrm{~ms}$

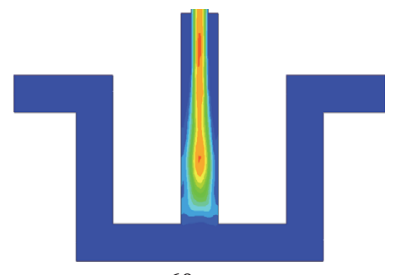

$60 \mathrm{~ms}$

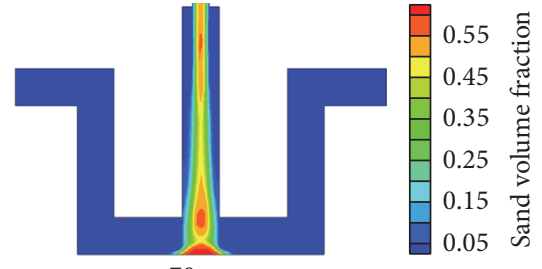

$70 \mathrm{~ms}$

(c)

FIGURE 11: Comparison of simulated maps of sand volume fraction for drag modification coefficient of (a) $C=1,(\mathrm{~b}) C=0.5$, and (c) $C=0.05$.

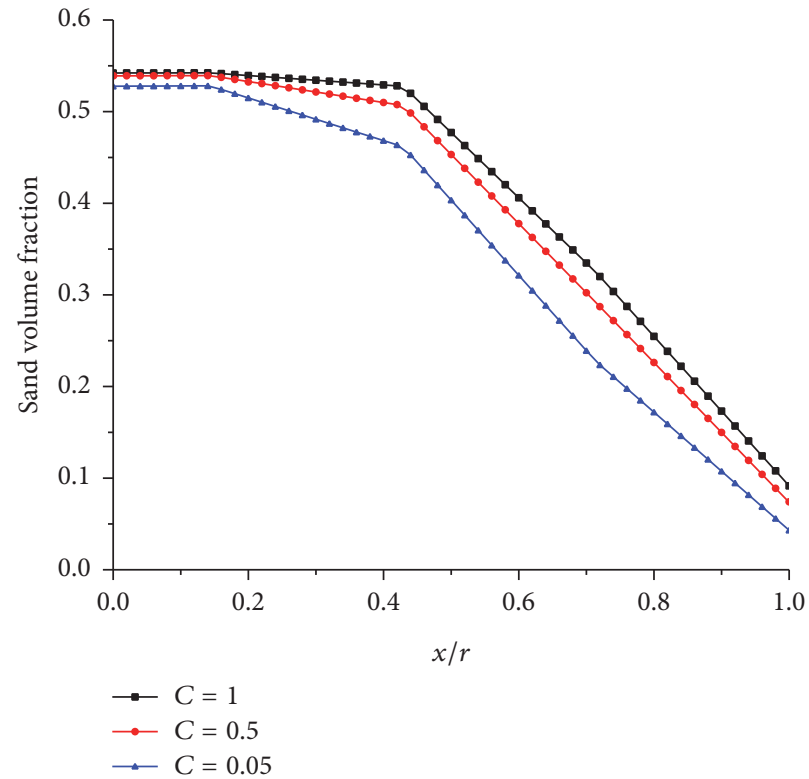

(a)

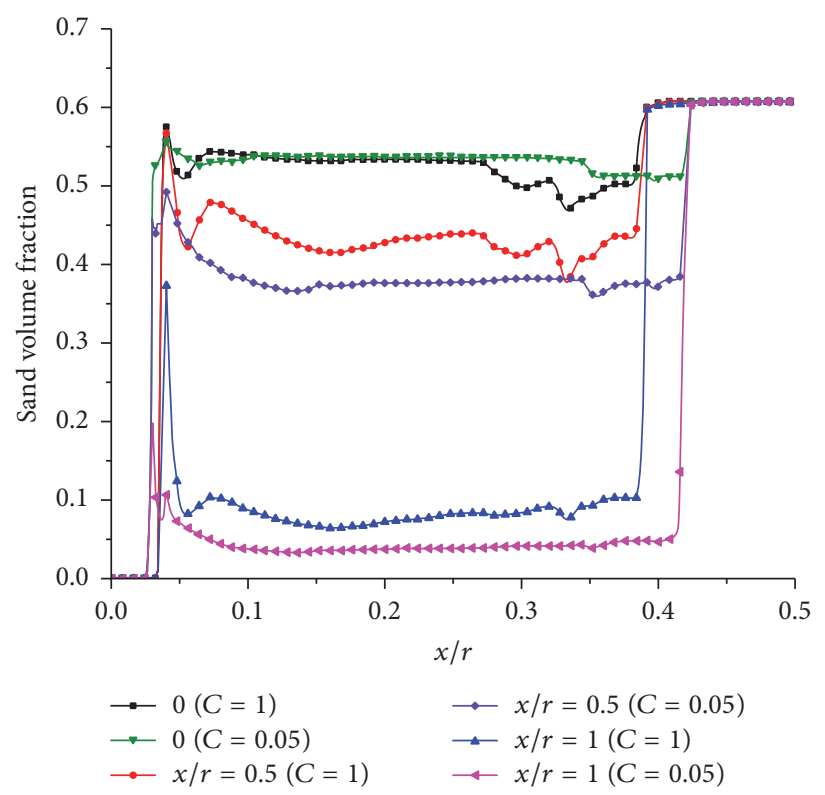

(b)

Figure 12: (a) The instantaneous sand volume fraction distribution at the nozzle ( $t=70 \mathrm{~ms})$ and (b) the variation of the sand volume fraction at nozzle over time ( $x$ is the distance to the axis and $r$ is the radius of the nozzle). 
(2) The region outside the angle range $\left(92^{\circ}\right)$ is characterized as the stagnant region and forms the "dead zone" in the shooting head. This region should be blocked to reduce the volume of "Dead zone" and thus increase the utilization of core sands.

(3) As the drag coefficient decreases, the dilation is suppressed and the sand volume fraction decreases dramatically at the region close to the border of the nozzle.

\section{Competing Interests}

The authors declare that they have no competing interests.

\section{Acknowledgments}

This work was supported by the National Science Foundation of China (Grant no. 51575304) and the National Science and Technology Major Project of the Ministry of Science and Technology of China (Grant no. 2012ZX04012011).

\section{References}

[1] S. I. Bakhtiyarov and R. A. Overfelt, "CFD modeling and experimental study of resin-bonded sand/air two-phase flow in sand coremaking process," Powder Technology, vol. 133, no. 1-3, pp. 68-78, 2003.

[2] F. Czerwinski, M. Mir, and W. Kasprzak, "Application of cores and binders in metalcasting," International Journal of Cast Metals Research, vol. 28, no. 3, pp. 129-139, 2015.

[3] A. Busciglio, G. Vella, G. Micale, and L. Rizzuti, "Analysis of the bubbling behaviour of 2D gas solid fluidized beds: part I. Digital image analysis technique," Chemical Engineering Journal, vol. 140, no. 1-3, pp. 398-413, 2008.

[4] G.-Q. Liu, S.-Q. Li, X.-L. Zhao, and Q. Yao, "Experimental studies of particle flow dynamics in a two-dimensional spouted bed," Chemical Engineering Science, vol. 63, no. 4, pp. 1131-1141, 2008.

[5] W. Pu, C. Zhao, Y. Xiong et al., "Numerical simulation on dense phase pneumatic conveying of pulverized coal in horizontal pipe at high pressure," Chemical Engineering Science, vol. 65, no. 8, pp. 2500-2512, 2010.

[6] J. Wu, Y. Cui, and W. Li, "A study on numerical simulation of core-shooting process," Journal of Materials Science and Technology, vol. 17, no. 6, pp. 625-628, 2001.

[7] J. Wu, Y. Cui, and W. Li, "Computer simulation of core-shooting process with two-phase flow," International Journal of Cast Metals Research, vol. 15, no. 4, pp. 445-449, 2002.

[8] B. Winartomo, U. Vroomen, A. Bührig-Polaczek, and M. Pelzer, "Multiphase modelling of core shooting process," International Journal of Cast Metals Research, vol. 18, no. 1, pp. 13-20, 2005.

[9] J. T. Jenkins and S. B. Savage, "Theory for the rapid flow of identical, smooth, nearly elastic, spherical particles," Journal of Fluid Mechanics, vol. 130, pp. 187-202, 1983.

[10] C. K. K. Lun, S. B. Savage, D. J. Jeffrey, and N. Chepurniy, "Kinetic theories for granular flow: inelastic particles in Couette flow and slightly inelastic particles in a general flowfield," Journal of Fluid Mechanics, vol. 140, pp. 223-256, 1984.
[11] J. Ding and D. Gidaspow, "A bubbling fluidization model using kinetic theory of granular flow," AIChE Journal, vol. 36, no. 4, pp. 523-538, 1990.

[12] D. Gidaspow, Multiphase Flow and Fluidization: Continuum and Kinetic Theory Descriptions, Academic Press, New York, NY, USA, 1994.

[13] D. E. Stock, "Particle dispersion in flowing gases-1994 freeman scholar lecture," Journal of Fluids Engineering, vol. 118, no. 1, pp. 4-17, 1996.

[14] A. Srivastava and S. Sundaresan, "Analysis of a frictional-kinetic model for gas-particle flow," Powder Technology, vol. 129, no. 13, pp. 72-85, 2003.

[15] R. Delannay, M. Louge, P. Richard, N. Taberlet, and A. Valance, "Towards a theoretical picture of dense granular flows down inclines," Nature Materials, vol. 6, no. 2, pp. 99-108, 2007.

[16] M. A. van der Hoef, M. van Sint Annaland, N. G. Deen, and J. A. M. Kuipers, "Numerical simulation of dense gas-solid fluidized beds: a multiscale modeling strategy," Annual Review of Fluid Mechanics, vol. 40, pp. 47-70, 2008.

[17] P. C. Johnson, P. Nott, and R. Jackson, "Frictional-collisional equations of motion for particulate flows and their application to chutes," Journal of Fluid Mechanics, vol. 210, pp. 501-535, 1990.

[18] D. G. Schaeffer, "Instability in the evolution equations describing incompressible granular flow," Journal of Differential Equations, vol. 66, no. 1, pp. 19-50, 1987.

[19] A. T. Andrews IV, P. N. Loezos, and S. Sundaresan, "Coarse-grid simulation of gas-particle flows in vertical risers," Industrial and Engineering Chemistry Research, vol. 44, no. 16, pp. 6022-6037, 2005.

[20] P. C. Johnson and R. Jackson, "Frictional-collisional constitutive relations for granular materials, with application to plane shearing," Journal of Fluid Mechanics, vol. 176, pp. 67-93, 1987.

[21] S. Benyahia, M. Syamlal, and T. J. O'Brien, "Study of the ability of multiphase continuum models to predict core-annulus flow," AIChE Journal, vol. 53, no. 10, pp. 2549-2568, 2007.

[22] S. H. Hosseini, G. Ahmadi, B. S. Razavi, and W. Zhong, "Computational fluid dynamic simulation of hydrodynamic behavior in a two-dimensional conical spouted bed," Energy and Fuels, vol. 24, no. 11, pp. 6086-6098, 2010.

[23] W. Du, X. Bao, J. Xu, and W. Wei, "Computational fluid dynamics (CFD) modeling of spouted bed: influence of frictional stress, maximum packing limit and coefficient of restitution of particles," Chemical Engineering Science, vol. 61, no. 14, pp. 4558-4570, 2006.

[24] X. Gao, C. Wu, Y.-W. Cheng, L.-J. Wang, and X. Li, "Experimental and numerical investigation of solid behavior in a gas-solid turbulent fluidized bed," Powder Technology, vol. 228, pp. 1-13, 2012.

[25] L. Huilin, D. Gidaspow, J. Bouillard, and L. Wentie, "Hydrodynamic simulation of gas-solid flow in a riser using kinetic theory of granular flow," Chemical Engineering Journal, vol. 95, no. 1, pp. $1-13,2003$. 

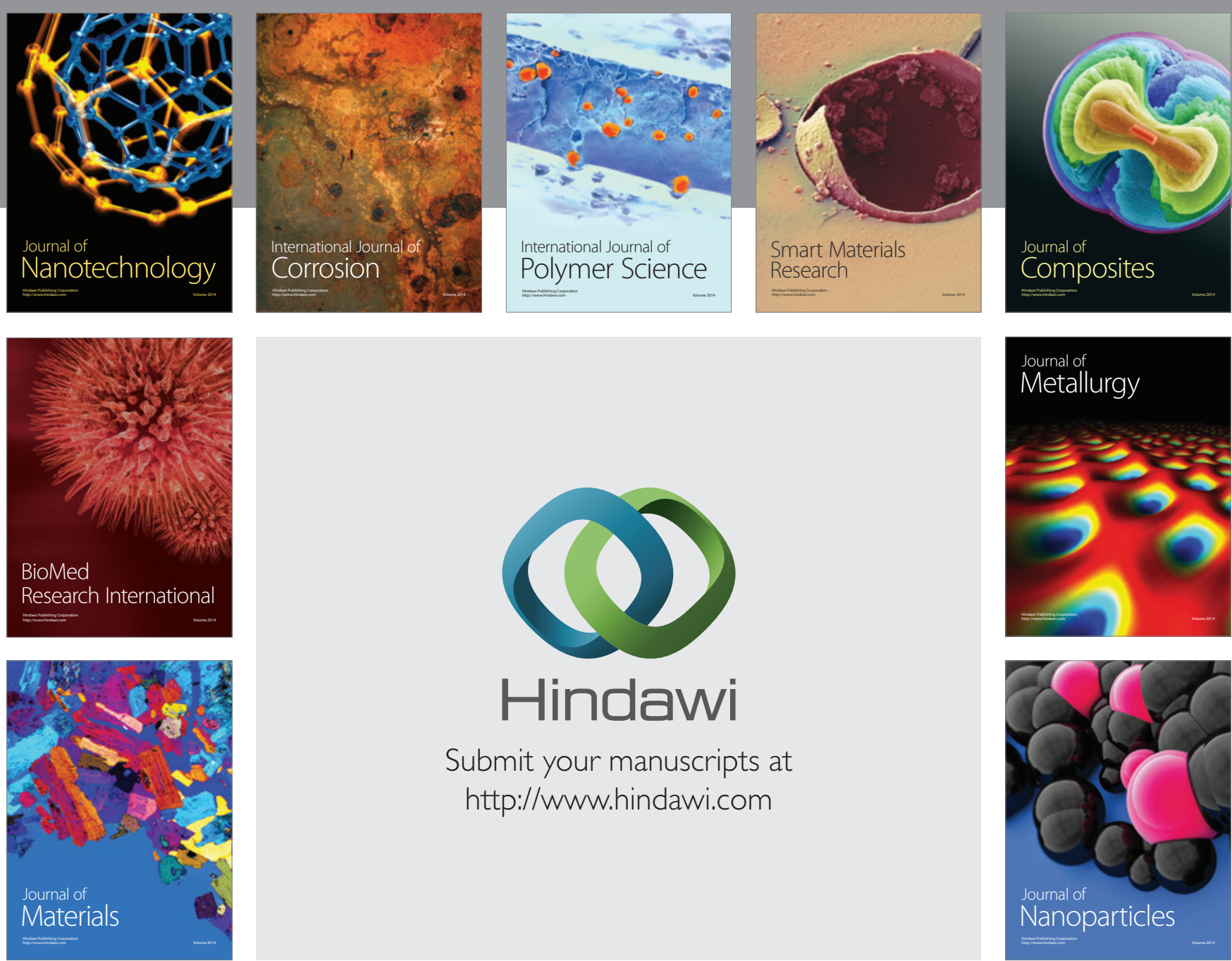

\section{Hindawi}

Submit your manuscripts at

http://www.hindawi.com

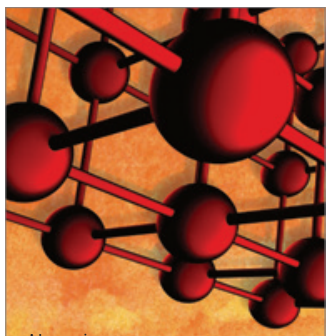

Materials Science and Engineering
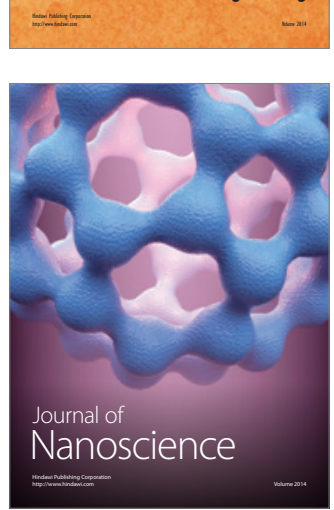
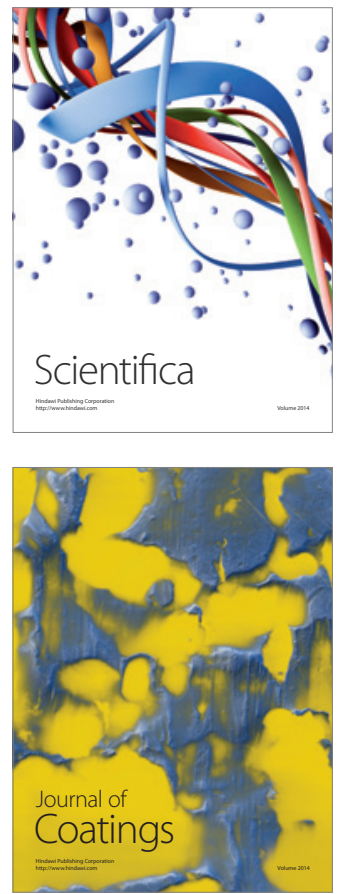
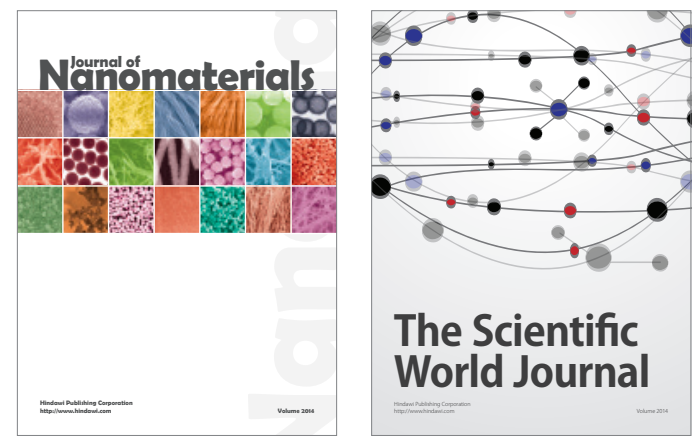

The Scientific World Journal
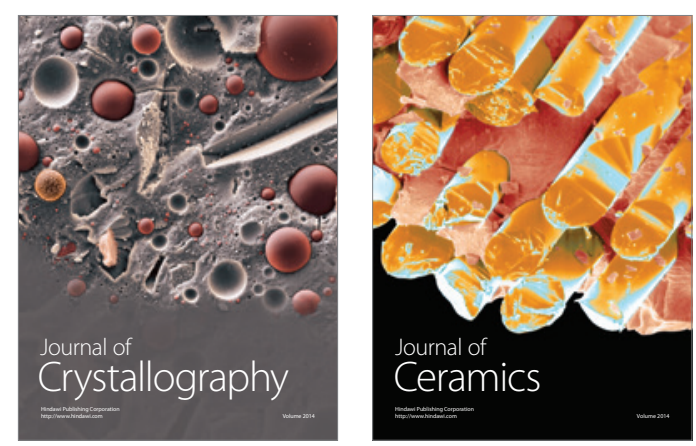
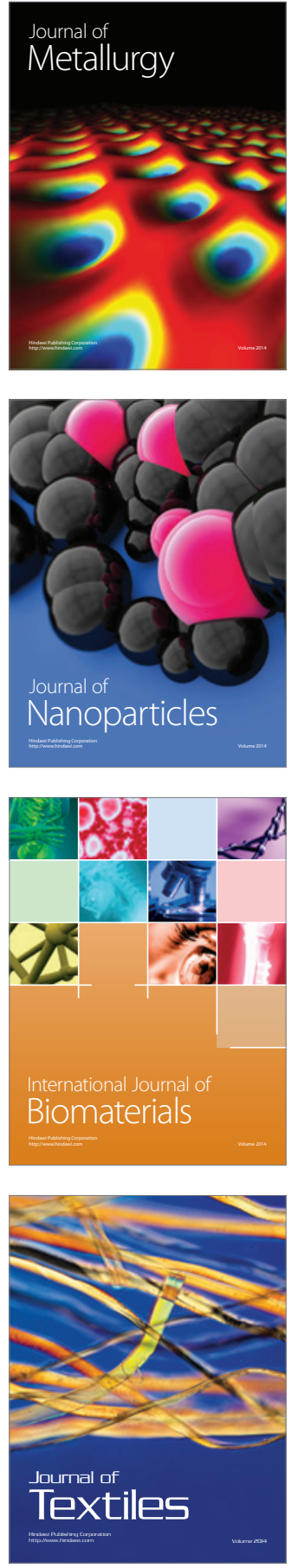